\title{
Gestão do trabalho, saúde e segurança dos trabalhadores de termelétricas: um olhar sob o ponto de vista da atividade
}

\author{
Labor management and the health and safety of thermoelectric \\ plant workers: a study from the viewpoint of the activity
}

Hilka Flavia Saldanha Guida ${ }^{1}$

Jussara Brito ${ }^{2}$

Denise Alvarez ${ }^{3}$

${ }^{1}$ Petroleo Brasileiro S.A. Petrobras. Av. Henrique Valadares 28, Centro.

20.231-030 Rio de Janeiro RJ Brasil.

hilka.guida@yahoo.com.br

${ }^{2}$ Escola Nacional de Saúde

Pública. Fiocruz.

${ }^{3}$ Programa de Pós-

Graduação em Engenharia

de Produção, Universidade

Federal Fluminense.
Abstract This article presents the labor management changes and the implications for occupational health and safety that occurred after two thermoelectric plants were acquired by a government-owned, joint stock with private investors, energy corporation. The changes led part of these workers to question their own professional abilities, as previously experienced workers were suddenly considered unqualified due to the new organizational model and restructuring implemented in their units. It was seen how lack of professional recognition in the workplace led to negative health and safety consequences for workers, as there were numerous cases of psychic anguish, emotional disorders, musculoskeletal problems, gastrointestinal disorders, etc. It was also seen that it is now possible to introduce a series of measures that can contribute to improve working conditions and, consequently, the lives of the workers. The benchmark used was Ergology, as well as aspects of the Psychodynamics of Work and the Ergonomics of the Activity. The methodology included a bibliographical survey of the theme, document analysis, semistructured interviews, systematic activities observations and the validation of results with the research subjects.

Key words Thermoelectric plants, Occupational health, Labor management, Productive Restructuring and Ergology
Resumo O artigo apresenta as mudanças na gestão do trabalho de duas termelétricas privadas, após serem adquiridas por uma Empresa de energia de economia mista, e suas implicações na saúde e segurança de seus trabalhadores. Estas mudanças fizeram com que parte desses trabalhadores questionasse sua própria capacidade laborativa, pois trabalhadores experientes tornaram-se de uma hora para outra inábeis em decorrência do modelo organizacional e das reestruturações implantadas em suas unidades. Constatou-se que a ausência de reconhecimento no trabalho trouxe consequências para a saúde e a segurança destes trabalhadores, pois houve inúmeros relatos de sofrimento psíquico, distúrbios emocionais, problemas osteomusculares, alterações gastrointestinais, etc. Evidenciouse que atualmente é possível introduzir uma série de medidas que podem contribuir para a melhoria das condições de trabalho e, consequentemente, da vida dessas pessoas. Utilizou-se o referencial teórico da Ergologia, assim como os aportes da Psicodinâmica do Trabalho e da Ergonomia da Atividade. O percurso metodológico envolveu: levantamento bibliográfico sobre o tema, análise documental, entrevistas semiestruturadas, observações sistemáticas da atividade e validação dos resultados com os sujeitos da pesquisa.

Palavras-chave Termelétricas, Saúde do trabalhador, Gestão do trabalho, Reestruturação produtiva e ergologia 


\section{Introdução}

Em 2004, uma empresa de petróleo do país decide diversificar a sua matriz energética, atuando também no setor de eletricidade. Paralelo a isto, o Brasil sofre com os apagões energéticos, gerando uma série de instabilidades neste setor, que é estratégico para a soberania nacional. Conforme sinaliza Rigotto ${ }^{1}$, tem sido crescente a demanda do Governo em ampliar a matriz energética e aumentar a sua segurança, sem alterar os padrões de consumo existentes. Neste contexto foi fortemente incentivada a construção das usinas termelétricas, apesar do seu alto custo e dos impactos ambientais.

Segundo a autora, no que tange à infraestrutura, um dos eixos de maior relevância no PAC é o de geração e transmissão de energia, que envolve os agrocombustíveis, usinas hidrelétricas ou termelétricas, a petroquímica, etc. Ela enfatiza ainda que a expansão da oferta de energia é relacionada, no discurso oficial, ao aquecimento da economia e à elevação do Produto Interno Bruto (PIB), através da atração e implantação de processos produtivos eletrointensivos como os de produção de alumínio e ferroligas, a siderurgia, petroquímica, celulose e papel.

Nesse contexto, o governo, que é sócio majoritário, decide que esta empresa assuma a gestão de grande parte do parque termelétrico brasileiro, composto na época por doze usinas. Parte destas unidades é adquirida com seu efetivo funcional, isto é, sem dispensa dos empregados, nem sua incorporação ao efetivo funcional da empresa compradora, passando esta a pertencer integralmente à de energia.

Este estudo busca discutir o processo de aquisição destas termelétricas sob o ponto de vista da atividade, compreendendo como a mudança de propriedade alterou o cotidiano de trabalho das pessoas nestas unidades. Compreende-se que a configuração organizacional atípica formada nestas termelétricas, onde empresas privadas foram incorporadas a uma empresa pública, foi fruto do processo de Reestruturação Produtiva às avessas, pois a Empresa de energia foi indicada pelo Governo Federal e participou dos consórcios com multinacionais estrangeiras e teve um papel de viabilizadora destes empreendimentos. Cabe sinalizar que a experiência vivenciada nestas termelétricas é bastante peculiar, pois eram empresas privadas e, em geral, o movimento de Reestruturação Produtiva tende à privatização das empresas públicas e nestas unidades ocorreu processo inverso: empresas privadas passam para a gestão de uma empresa de economia mista, onde o governo é o acionista majoritário.

Devido a esses fatores, a escolha do grupo estudado, a dos empregados das termelétricas, não foi aleatória por se acreditar que o vínculo criado nestas unidades expressa uma nova faceta da Reestruturação Produtiva. Pressupõe-se que a forma de inserção diferenciada destes trabalhadores trouxe uma série de implicações no cotidiano de trabalho deste grupo.

Destaca-se a relevância da temática deste estudo e sua atualidade, no que se refere à análise das situações de trabalho e as implicações das mudanças organizacionais, advindas da Reestruturação Produtiva, na saúde e na segurança dos trabalhadores da indústria de processo contínuo.

Os objetivos específicos do estudo foram analisar o processo de aquisição das termelétricas A e B e compreender as mudanças ocorridas na gestão do trabalho das termelétricas face à aquisição pela Empresa de energia procurando conhecer como o vínculo de trabalho se efetiva no cotidiano e na atividade destes trabalhadores, evidenciando assim as implicações das mudanças organizacionais na saúde e segurança.

\section{Caminhos teóricos-metodológicos}

Estudo exploratório de caráter qualitativo que pretendeu conhecer a realidade profissional dos trabalhadores lotados nas unidades A e B e que tiveram seu cotidiano de trabalho modificado, após a aquisição das termelétricas por uma Empresa de energia.

Foi utilizado o referencial teórico da Ergologia e alguns conceitos específicos de outras correntes teóricas (Ergonomia da Atividade e Psicodinâmica do Trabalho) assim como a concepção de saúde de Canguilhem. O diálogo entre conceitos oriundos de diferentes abordagens, sob a perspectiva ergológica, contribuiu sinergicamente para a análise do objeto deste estudo.

O aporte teórico da Ergologia possibilitou a compreensão do sentido enigmático e complexo das situações de trabalho vivenciadas pelos empregados próprios das duas termelétricas que foram objeto deste estudo. De modo sintético entende-se Ergologia como:

[...] não é uma disciplina no sentido de um novo dominio do saber, mas, sobretudo, uma disciplina do conhecimento. Essa disciplina ergológica é própria às atividades humanas e distinta da disciplina epistêmica que, para produzir saber e conceito no campo das ciências experimentais deve, ao contrá- 
rio, neutralizar os aspectos históricos. A démarche ergológica, mesmo tendo como objetivo construir conceitos rigorosos deve indicar nestes conceitos como e onde se situa o espaço das (re) singularizações parciais, inerentes às atividades de trabalho ${ }^{2}$.

Esta perspectiva considera que todo trabalho se faz através da confrontação do homem no trabalho com as normas e valores antecedentes em um dado momento histórico que é sempre singular. Dentro do vasto universo conceitual presente na perspectiva ergológica elegeu-se alguns conceitos para balizar e nortear as reflexões tecidas neste artigo. Não se pretende aqui cristalizar os conceitos em definições fechadas e conclusas, entendendo-os como algo inacabado, incompleto, em permanente construção e reconstrução. Procurou-se elencá-los evocando alguns de seus sentidos e possibilidades para que o leitor possa melhor compreender a orientação presente no estudo. Os conceitos selecionados foram:

Normas antecedentes: apesar de não haver diferença de natureza entre a noção de normas antecedentes e de trabalho prescrito tende-se a considerar a primeira mais ampla que a segunda na medida em que as normas antecedentes cristalizam de forma codificada as aquisições de inteligência, da experiência coletiva e dos poderes estabelecidos. De caráter híbrido elas podem ser caracterizadas por três aspectos: abarcam restrições de execução heterodeterminadas; são construções históricas, isso é, dizem respeito a um patrimônio cientifico cultural e, finalmente, indicam valores do bem comum, do bem viver ${ }^{3}$.

Renormatizações das situações de trabalho: busca evidenciar que na realização da atividade de trabalho há sempre um debate entre o trabalhador (individualmente e coletivamente) e o meio, onde é sempre necessário fazer escolhas para a realização de seu trabalho. Portanto, trabalhar é sempre gerir, tomar decisão, escolher, mesmo que a nível micro.

O trabalho como dramáticas do uso de si: entendendo que o trabalhar envolve sempre mobilização do sujeito, em um espaço de tensões, de negociações e confrontações entre normas e valores. E que nesse espaço de tensões há drama, há história, algo se passa. O trabalho como uso de si por outrem se refere ao que é posto no cotidiano de trabalho, às normas, aos procedimentos, às condições de trabalho. Tratam-se das regras heterodeterminadas que não são seguidas sem que se trave um debate, tanto consigo próprio quanto com os outros.

Além disso, o esquema do espaço tripolar foi utilizado de modo a compreender o cotidiano dos trabalhadores das termelétricas que tiveram seus trabalhos modificados e influenciados (e influenciaram) pela tensão dialógica dos três polos presentes. Entende-se espaço tripolar, de acordo com Schwartz e Durrive ${ }^{4}$, como um lugar onde lógicas distintas e algumas vezes divergentes estão em permanentes tensões, dinamizando a história, sendo representadas por três polos distintos: o polo do mercado, o polo do político e o polo da atividade.

O polo do mercado refere-se às questões econômicas do gerenciamento do trabalho, onde, em geral, os administradores da organização estão focados nas questões contábeis, financeiras, comerciais, enfim no valor econômico do trabalho. Já o polo do político é o que deve gerenciar o bem comum, encarregado dos valores não dimensionáveis e por fim, mas não menos importante o polo da atividade, aquele referente às gestões do trabalho e no trabalho, o trabalho como uso de si.

Para a Ergologia, o trabalho é visto como um lócus permanente de decisões, de escolhas e de um constante debate de normas e valores, interessando o que de fato o trabalhador faz em sua atividade real de trabalho e o que deixa de fazer, ou seja, seus impedimentos, pois ambos constituem a sua atividade.

A opção pela Ergologia se justifica pela natureza do objeto - ver de perto as consequências das mudanças organizacionais - pois, conforme sinaliza Schwartz ${ }^{5}$, o trabalho por si só é complexo e enigmático, portanto, impossível de ser apreendido por um único campo de saber. Buscou-se analisar as mudanças no trabalho, evitando realizar julgamentos de valores a priori, pois não é possível conhece-lo sem ouvir quem o exerce, sem compreendê-lo em sua amplitude e complexidade. A partir desta compreensão foi possível realizar uma reflexão acerca das mudanças organizacionais e as implicações destas alterações na saúde e segurança destes trabalhadores ${ }^{6}$. Para isso, faz-se necessária a interlocução de vários campos de conhecimento, de modo a desvelar as múltiplas facetas do trabalho, que nada tem de simples e trivial.

[...] coisa enigmática que ele [o trabalho] cristaliza em si atravessa e circula entre as diversas formas de atividade das quais algumas têm a forma 'emprego' e outras não: trabalho para si ou sobre si, trabalho doméstico, militante, estratégico, politico. Toda forma de atividade em qualquer circunstância requer sempre variáveis para serem geridas em situações históricas sempre em parte singulares, portanto escolhas a serem feitas, arbitragens - 
às vezes quase inconscientes - portanto, o que eu chamo de uso de si, usos dramáticos de si. Simplesmente, em nossa época, é verdade que a forma do trabalho como emprego ou mercadoria é, de um modo geral, quer dizer, nem sempre, o modo mais rico de ativação dentre estes modos 'dramáticos'.

Conjugado à perspectiva ergológica utilizouse o conceito de saúde de Canguilhem ${ }^{7,8}$. Para este autor, a doença e a saúde são dois fenômenos distintos, configurando-se em dois modos de vida, portanto, tanto a doença como a saúde são aspectos da vida. Normal entendido como uma norma de vida, como movimento individual, biológico e psicológico em busca da saúde, a capacidade de lidar com as variabilidades do meio, que é sempre infiel, renormatizando-o. Nesse contexto a saúde refere-se à capacidade de adoecer e sair do estado patológico.

Ao entender que não existe este estado de perfeição nem de equilíbrio permanente e sim que tanto a saúde como a doença são um processo em movimento e inerente à vida também se compreende, conforme sinalizam Brito et al. ${ }^{9}$, que a saúde não é algo exterior ao indivíduo, assunto exclusivamente dos especialistas, mas de todas as pessoas, pois cada ser humano irá vivenciar o seu processo saúde-doença de forma singular.

"Não se pode dispensar ou substituir aquele que vive a experiência por alguém de fora, exterior à experiência. A contribuição das ciências, nesse caso, é imprescindível, necessária, mas não suficiente" 9 .

A Ergologia irá explorar em seus debates esta concepção vitalista de saúde desenvolvida por Canguilhem.

Ser sadio significa não apenas ser normal numa situação determinada, mas ser, também, normativo, nessa situação e em outras situações eventuais. O que caracteriza a saúde é a possibilidade de ultrapassar a norma que define o normal momentâneo, a possibilidade de tolerar infrações à normal habitual e de instituir normas novas em situações novas $^{10}$.

Outro aporte teórico utilizado foi a Psicodinâmica do Trabalho, com sua análise sobre os sistemas defensivos elaborados pelos trabalhadores, tanto individualmente como coletivamente, com caráter ideológico ou estratégico ${ }^{11}$. Entendem-se como sistemas defensivos a conduta individual ou coletiva com o objetivo de adaptação e proteção, em prol da manutenção da sua saúde embora nem sempre benéficas ao trabalhador. Assim, o adoecimento pode representar uma falha na forma de defesa adotada, uma impossibilidade frente à situação posta. Podem ser conscientes ou inconscientes e de vários tipos, tais como banalização, servidão, aceleração, compensação, dentre outras.

Outra contribuição da Psicodinâmica do Trabalho para esta análise refere-se ao estudo da dinâmica do reconhecimento. Para Dejours ${ }^{12} \mathrm{o}$ reconhecimento está diretamente associado ao binômio contribuição-retribuição, sendo fundamental para mobilização subjetiva dos sujeitos. De um lado, o reconhecimento da hierarquia, que perpassa a utilidade social ou produtividade, e relaciona-se às contribuições advindas do trabalhador para a organização ${ }^{13}$. Do outro, o julgamento da estética, onde os pares e colegas reconhecem o valor do trabalho do indivíduo. Estes dois julgamentos trazem uma identidade ao trabalhador e um sentido a este trabalho e são compreendidos como retribuições moral e simbólica às contribuições efetuadas por este trabalhador.

Além dessas ferramentas teóricas, utilizou-se alguns conceitos oriundos da Ergonomia da Atividade. Figura como uma das maiores contribuições deste campo a conceituação de trabalho real versus trabalho prescrito, no qual pode ser evidenciado que o trabalho humano nunca é meramente execução de uma tarefa e sim uma atividade investida de inteligência para dar conta das variabilidades, que podem ser relacionadas ao sistema sociotécnico, à organização do trabalho, enfim a uma série de fatores que se apresentam no momento da situação de trabalho e não são previsíveis. Brito et al. ${ }^{9}$ sinalizam que o trabalho prescrito ou a tarefa está associado às regras e objetivos estabelecidos pela organização do trabalho e as condições que são dadas, enfim a tarefa estabelece o que deve ser feito. Por outro lado, o trabalho real ou a atividade é o que de fato é feito pelo trabalhador, como este se mobiliza para alcançar os objetivos propostos. Atividade neste contexto é vista como elemento congregador, como elemento unificador de naturezas diversas:

[...] uma resposta aos constrangimentos determinados exteriormente ao trabalhador, e ao mesmo tempo, é capaz de transformá-los. [...] Ela unifica a situação. As dimensões técnicas, econômicas, sociais do trabalho só existem efetivamente em função da a tividade que as põe em ação e as organiza ${ }^{14}$.

Outro importante conceito oriundo da Ergonomia da Atividade refere-se à atividade coletiva de trabalho, onde esta não é meramente uma sobreposição de indivíduos, cada qual unilateralmente desenvolvendo sua atividade, mas sim um conjunto de pessoas voltadas para o alcance de um objetivo comum. Esta dimensão coletiva 
do trabalho possibilita a configuração de diferentes tipos de coletivos de trabalho, já identificados por Guerin et al. ${ }^{14}$ e complementado por Athayde ${ }^{13}$, que acrescenta à classificação original um coletivo de rede:

- Coletivo de Tarefa: quando há colaboração explícita para a realização de uma mesma tarefa;

- Coletivo de linha: quando aspectos coletivos manifestam-se somente nos resultados do trabalho (a informação circula);

- Coletivo de Obra: quando há atividade simultânea de trabalhadores perseguindo objetivos diferentes, em interface;

. Coletivo de Regulação: quando a dimensão coletiva manifesta-se pelo papel organizador de certos trabalhadores;

. Coletivo de Rede: quando a dimensão coletiva atravessa todas as atividades de trabalho, sendo engendrada antes, durante e depois da situação de trabalho.

No que se refere aos procedimentos e condutas adotadas neste estudo foram seguidas as recomendações da Resolução 196/96 ${ }^{15}$ de Ética de Pesquisa em Seres Humanos. De tal forma que todos os sujeitos foram esclarecidos sobre os objetivos da pesquisa e aceitaram participar do estudo voluntariamente, tendo assinado o Termo de Consentimento Livre e Esclarecido, que foi elaborado pela própria autora e buscava esclarecer aos potenciais sujeitos da pesquisa sobre os objetivos desta e os possíveis riscos e benefícios identificados com a sua participação.

Os critérios que nortearam a escolha dos participantes do estudo foram os seguintes: ser empregado próprio da termelétrica; ser lotado nas termelétricas A e B; ser voluntário, tendo que atender a todos estes critérios acima simultaneamente. Além disso, dentre o conjunto de trabalhadores optou-se em entrevistar os trabalhadores que possuíam função gerencial (gerentes, coordenadores e supervisores) antes do processo de aquisição e trabalhadores da área de operação e manutenção das duas termelétricas. Atendendo a esses critérios participaram voluntariamente vinte e oito trabalhadores de ambos os sexos, e de diferentes idades e nível de escolaridade, tendo, todos eles, o tempo médio de serviço nas termelétricas, de sete a nove anos.

Quanto à caracterização pessoal, registrouse que foram entrevistados vinte e dois homens e seis mulheres; a faixa etária variou entre 26 e 57 anos. Tivemos 19 participantes de nível superior, sendo que, deste universo classificado como de nível superior, foram identificados cinco trabalhadores com mestrado e sete com especializa- ção e 09 de nível médio, evidenciando o alto grau de especialização desta força de trabalho.

Quanto à caracterização profissional, todos foram incorporados à Empresa de energia, após aquelas em que trabalhavam (iniciativa privada) terem sido compradas integralmente pela empresa de economia mista; quatro trabalhadores formalmente ocupavam cargos gerenciais antes do processo de aquisição, tendo até hoje as suas respectivas carteiras de trabalho assinadas com a função gerencial, mas não exercendo mais oficialmente esta função. Outros sete trabalhadores exerciam função de coordenação e supervisão também oficialmente reconhecida pelas termelétricas.

\section{Resultados e discussão}

Identificou-se que o processo de aquisição de empresas privadas à Empresa de energia trouxe a essas termelétricas uma configuração organizacional atípica, pois além dos empregados próprios da Empresa de energia e dos terceirizados, somase ao quadro de trabalhadores na empresa uma nova figura, o próprio termelétrica. Cada uma dessas categorias contratuais com patamares de direitos e reconhecimento distintos entre si.

De um lado, os empregados petroleiros, com seus direitos reconhecidos, empregos estáveis, em funções gerenciais e de supervisão de equipe, com uma identidade funcional e reconhecidos como empregados da Empresa de energia, denominados por um trabalhador como empregado de primeira categoria. De outro, o próprio termelétrica, um híbrido, com certa estabilidade empregatícia, tendo em vista que a sua empresa passou a pertencer à Empresa de energia, com Acordo Coletivo de Trabalho que lhes garantem alguns direitos, mas longe de alcançar os patamares de direitos e reconhecimento fornecido aos trabalhadores da Empresa de energia, portanto, um empregado de segunda categoria. Vale sinalizar que a aquisição pela Empresa de energia trouxe uma estabilidade empregatícia, pois anteriormente eram contratados pela iniciativa privada $\mathrm{e}$ pelas leis do mercado. E por último, os trabalhadores terceirizados, sem nenhuma estabilidade em seus empregos, facilmente dispensáveis, descritos por Harvey ${ }^{16}$ como periféricos, portanto, um empregado de terceira categoria.

Reitera-se que o vínculo empregatício dessas pessoas é uma espécie de híbrido e não está descrito na literatura científica da atualidade ${ }^{16,17}$, pois não são trabalhadores estáveis tais como estatutários, não são empregados públicos tais como 
os da Empresa de energia, tampouco são terceirizados, quarterizados ou subcontratados.

Em 2009, a Empresa de energia elaborou e implementou um Plano de Classificação e Avaliação de Cargos (PCAC) dos empregados das termelétricas. A partir daí foi instituído nos Acordos Coletivos de Trabalho (ACT) de todas as termelétricas o plano de carreiras, que tinha como objetivo avaliar o desempenho anual de todos trabalhadores e conceder aumento no nível salarial e progressão na carreira funcional, em virtude do desempenho profissional. Verificou-se que nas duas termelétricas alguns trabalhadores não foram enquadrados no PCAC, em decorrência da função que exerciam ou dos salários recebidos, tornando-se extraplanos.

Esta distinção trouxe instabilidade e insegurança para os extrasplanos, pois anteriormente cada termelétrica constituía um grupo homogêneo, sem diferenciação e, com a criação do PCAC, estes não receberam alguns benefícios fornecidos ao conjunto dos trabalhadores, sendo reajustados os seus salários pelos índices da inflação. Dessa forma, permaneceram estagnados nas suas carreiras, não sendo avaliados por seus desempenhos profissionais. Um trabalhador denomina a sua atual situação profissional como uma regressão funcional, enquanto os outros têm uma progressão funcional.

Evidenciou-se, também que esta distinção trouxe um significativo enfraquecimento do coletivo, onde muitos desistiram de lutar, decidiram remar junto à maré, pelo fato de não obterem êxito nas lutas. O reflexo dessa estratégia é manifestado por meio de acomodação, desânimo, desprazer com a realização de suas atividades e frustração por não serem solicitados de acordo com suas competências e habilidades.

Hoje, apesar de terem ciência que a situação funcional não está totalmente resolvida, evidenciam que o medo e a insegurança diminuíram substancialmente, pois acreditam que com o passar dos anos fica cada vez mais difícil para a Empresa de energia demiti-los sumariamente. No âmbito das conquistas econômicas se avançou substancialmente e diversos benefícios foram conquistados, contudo há muito ainda que se modificar no reconhecimento, na valorização e no sentido de pertencimento deste grupo ao efetivo funcional da Empresa de energia, quer seja como empregado petroleiro ou como empregado de uma subsidiária da Empresa de energia.

Outra questão extremamente significativa, relevante e simbólica refere-se à ausência de um crachá funcional, que os identifique tal como os demais empregados da Empresa de energia ou como empregados terceirizados. Considerando que o crachá é a chave de entrada para todas as unidades da Empresa de energia, a ausência de uma identificação funcional, conforme a padronização existente na estrutura organizacional traz dificuldades de acesso em outras instalações e também não os identifica como trabalhadores pertencentes à Empresa de energia, tal como qualquer trabalhador petroleiro ou de subsidiária.

A identificação funcional da Empresa de energia é bastante padronizada permitindo que qualquer trabalhador seja identificando, de acordo com seu vínculo empregatício, a depender da cor de seu crachá. Entretanto, estes trabalhadores não pertencem a nenhum dos dois grupos funcionais existentes na estrutura de gestão da Empresa de energia, sendo em cada termelétrica utilizada uma cor de crachá, por exemplo, o crachá da Termelétrica $A$ é lilás e o da Termelétrica $B$ é da cor branca.

Verificou-se também que ambas as termelétricas permaneceram praticamente sem realizar despachos energéticos durante os primeiros dois anos da incorporação à Empresa de energia. Este período de interrupção da operação criou a representação entre os trabalhadores de que a Empresa de energia os via como dispensáveis para o processo. Representação incentivada pelo fato das termelétricas não serem lucrativas e rentáveis, naquele momento, à Empresa de energia, reforçando a ideia de que, a qualquer momento, as termelétricas seriam desmontadas e os trabalhadores demitidos.

Isso trouxe uma série de reflexos para o cotidiano desses trabalhadores, pois houve um esvaziamento de suas atividades, tornando-as mais rotineiras, burocráticas e pautadas na área administrativa. Entretanto, mesmo com a redução das atividades, são efetuadas contratações de mão de obra terceirizada, especialmente na área administrativa das termelétricas. Tal fato fez com que muitos destes trabalhadores acreditassem que, tão logo o trabalho fosse absorvido pelos novos contratados, seriam substituídos.

Em face desse contexto foi criada uma situação de rivalidade, sobreposição de papéis, que dificultou o processo de cooperação e solidariedade nos coletivos de trabalhos, pois os colegas de trabalho não se identificam como pares, mas sim rivais ou concorrentes. Em alguns casos, as adversidades organizacionais viraram problemas pessoais, gerando conflitos de relacionamento interequipe. Sob esse aspecto viu-se concretamente que o contexto de rivalidade no ambiente de trabalho pode proporcionar o enfraquecimen- 
to dos coletivos de trabalho como afirma Dejours ${ }^{11}$. Esse fenômeno prejudica as relações de solidariedade, cooperação entre os indivíduos e, este enfraquecimento, induz a uma dificuldade nas interelações de trabalho e, em alguns casos, gera sofrimento patogênico.

Acrescenta-se ao bojo da discussão o fato de não se ter identificado que estes trabalhadores (próprios, termelétricas e terceirizados) juntos tenham constituído um Coletivo de Rede, mas sim um Coletivo de Tarefa. Para a realização das atividades cotidianas, estes trabalhadores necessitam ter uma rede colaborativa para obtenção dos resultados, mas não se identificou a construção de uma história partilhada, uma construção histórica do e no trabalho.

Assim, a terceirização neste contexto pode ser compreendida como uma das modalidades de organização da produção na atualidade, que gera nos trabalhadores uma amputação de sua história coletiva, conforme descreve $\mathrm{Clot}^{18}$. Estes trabalhadores anteriormente tinham um saber acumulado, uma experiência, modos de vida e de trabalho e foi introduzida uma nova forma de organização, que requereu transformações nas atividades e trouxe à tona novas problemáticas a serem respondidas por essas pessoas.

De tal maneira que uma série de situações de desconforto, constrangimento e de embate é relatada por esses trabalhadores quando necessitam, por exemplo, realizar um treinamento in company ou participar de uma reunião na própria sede da Empresa. Nessas ocasiões necessitam se justificar, explicar que sua empresa foi adquirida pela Empresa de energia, que é uma subsidiária, porém ela não existe oficialmente nos sistemas tal como as demais. Este fato faz com que esses trabalhadores, necessitem de prévia autorização para circularem nestes ambientes como se fossem visitantes na própria empresa, a que estão subordinados. A ocorrência dessas situações parece acarretar uma ausência de sentimento de pertencimento, não se sentem inseridos, fazendo com que não se sintam trabalhadores próprios da empresa e, muitas vezes, não saibam definir sua vinculação profissional, tamanha é a indefinição de seu quadro contratual.

Ao expor esta problemática enfatizando o ponto de vista da atividade buscou-se evidenciar como um processo de cunho organizacional pode trazer consequências para a vida e o trabalho das pessoas dessas unidades. Procurou-se fazer emergir o movimento vital destes trabalhadores e a luta para a conquista de melhoria das condições de trabalho, explicitados nos embates, nas difi- culdades do dia a dia, pois conforme sinaliza Oliveira et al. ${ }^{19}$ a situação de trabalho compreende uma série de fatores tais como organização, condições e relações e as modificações no seu mundo trazem uma série de mobilizações para os trabalhadores e convocam o seu engajamento subjetivo na busca de soluções para o enfrentamento das situações postas e estes não estão passivos as alterações, mas também atuam e operam as mudanças em seu ambiente laboral.

A situação de trabalho é um conjunto de meios físicos, de objetos materiais e simbólicos, de sujeitos humanos, de tecnologia, de hierarquias e de organização, mas é também o resultado de escolhas organizacionais referindo-se aos objetivos e aos meios para atingi-los: as escolhas de ação, a realização das ações relativas a sujeitos específicos, aos meios, aos objetos, às técnicas. Esse conjunto está em permanente mudança, seja pelas inovações tecnológicas, seja pelas alterações organizacionais ${ }^{19}$.

Assim, evitaram-se as visões e profecias fatalistas, deterministas que não vislumbram nenhuma saída. Em seu lugar procurou-se dar voz às diferentes possibilidades, às diversas saídas, à negação da visão de um só caminho. Aposta-se então na percepção de que os trabalhadores nunca são passivos, alienados neste processo e que resistem às dificuldades enfrentadas, fazendo uso de si para gerir as situações de trabalho, em uma verdadeira tensão, uma dramatização do uso de si para tornar o meio vivível, isto é, possível, conforme sinaliza Schwartz ${ }^{20}$. A fala a seguir expressa esse movimento vital de um trabalhador para manter-se saudável, apesar da adversidade do ambiente de trabalho, as inúmeras dramáticas do uso de si para tornar esse ambiente vivível:

Eu há quatro anos e pouco estavam com $97 \mathrm{kgs}$ e hoje estou com $79 \mathrm{~kg}$, Vinte quilos a menos. Porque eu resolvi brigar e parar. Quarenta e sete anos, fase crítica de você ter infarto. Meu pai é cardíaco, com problemas sérios. Teve problemas várias vezes. Aquela coisa toda e eu com quarenta e tantos com esse nível de adrenalina. Eu pensei: eu vou infartar e não é isso que eu quero! Porque também quando você infarta. Você é colocado de lado né. Então também não serve de nada. Então eu falei não... Não é essa empresa que vai me derrubar. [...] Tenho um contrato. Eu sei muito bem das minhas obrigações. Eu tenho que cumprir elas direitinho. A partir daí é minha vida. Eu vou cuidar da minha vida. A partir daí eu to conseguindo reverter todo esse meu quadro, que é bastante emocional. Geralmente problemas de coluna, problemas físicos e respiratórios tá muito vinculado a problemas 
emocionais, vinculados a parte de estresse essa coisa toda, que é o que te prejudica. Então quando você começa a corrigir isso é que você começa a ficar mais centrado, mais legal, mas assim a saúde minha foi lá embaixo (Trabalhador Y).

Além disso, buscou-se com esta análise ver esse processo como uma dialética, isso é, como uma relação dialética entre o global e o local, entre esse processo de aquisição como uma opção de negócio e as implicações dessas mudanças no cotidiano destes trabalhadores, buscou-se, conforme ensina $\mathrm{Schwartz}^{20}$, recusar visões restritivas. Nestes cenários, somente a dimensão macro é responsável por promover impactos sobre as pessoas, onde os trabalhadores devem simplesmente se adaptar às mudanças. Por outro lado, também não se podem limitar as visões micro do trabalho, não considerando as questões macro para realização das análises e compreender a problemática, ora posta em questão. Sendo assim, se fez necessário realizar esforços para compreender o trabalho através das singularidades das suas situações, analisando conjuntamente as questões macroestruturais que trouxeram implicações para a atividade.

As alterações organizacionais nas UTE $A$ e $B$ em decorrência da mudança de propriedade trouxeram implicações na saúde dos trabalhadores. Foram relatados inúmeros adoecimentos, afastamentos do trabalho e sofrimento psíquico em decorrência destas mudanças.

A partir das fontes de dados verificou-se que no ano de 2010 (até outubro) havia a ocorrência de 172 dias perdidos por motivo de saúde. Entretanto, não há como saber os motivos dos afastamentos de saúde, pois as informações se referem estritamente aos dias de atestados e não constam informações sobre a patologia nos registros. Em 2009, os afastamentos de saúde contabilizaram 152 dias.

Na unidade $B$, os afastamentos foram por períodos mais prolongados e tiveram uma maior severidade, tendo sete trabalhadores se afastado das atividades laborativas por períodos superiores há quinze dias no período de 2006 a 2010. As doenças que afastaram os trabalhadores por benefício previdenciário neste período foram: Distúrbio Osteomuscular relacionado ao trabalho - DORT, acidentes de trabalho e neoplasias. Nesta unidade, no ano de 2010, consta o registro de 975 dias de ausência do trabalho por motivo de doenças no universo de 51 empregados próprios das termelétricas.

Na termelétrica $A$, de treze entrevistados, dez trabalhadores relataram implicações em sua saú- de e relacionam este processo de adoecimento às mudanças organizacionais decorrentes do processo de mudança e/ou relacionam ao seu processo de trabalho atual. As maiores queixas se referem ao estado de tensão, nervosismo, malestar generalizado em decorrência de situação de instabilidade, algumas doenças osteomusculares, hipertensão arterial, estresse, ansiedade, hérnia de disco, dentre outras patologias. Porém, apesar da maioria ter identificado um agravamento da sua saúde, tendo muitos realizado tratamentos tais como fisioterapia, acompanhamento especializado, uso de medicação contínua, a maior parte não se afastou de suas atividades laborativas, tendo suportado o adoecimento e permanecendo trabalhando.

Verificou-se também além das queixas e dos casos de adoecimentos que houve em diversos relatos dos trabalhadores movimentos de resistência, de dar a volta por cima e superar a adversidade. Dentre os inúmeros exemplos destacamos dois trabalhadores que tiveram esse movimento vitalista em prol das suas saúdes. O primeiro refere-se a um trabalhador do sexo masculino e 47 anos. Atualmente encontra-se bem de saúde, optou em enfrentar as adversidades falando claramente sua posição, não aceitando imposições de regras contraditórias e com isso, segundo ele, ganhou mais respeito do corpo gerencial.

O próprio trabalhador relata que tinha um problema de coluna crônico, mas estabilizado durante bastante tempo, mas que face às mudanças houve um agravamento da sua situação de saúde e isso fez com que por vários períodos ficasse totalmente imóvel em uma cama, sem condições mínimas de permanecer de pé. A seguir a fala deste trabalhador sobre o seu processo de adoecimento:

Então o que aconteceu eu tenho problemas sérios de coluna e principalmente na região lombar. Então eu fiquei por várias vezes entrevado [...]. Então quando eu começo a ficar muito nervoso, muito chateado e muito deprimido com a situação toda. Aquilo você vai contraindo tudo e dá alguns pinçamentos. Eu fico praticamente entrevado, Eu fico imóvel só mexendo os olhinhos. Não dá para mexer braço, não dá para mexer perna, não dá para mexer nada e por muitas vezes eu me vi nessa situação em casa, sem ter condições de vir trabalhar por causa dessa situação. Ter que sair rolando pela cama, me segurando pela janela para tentar levantar, para tentar por a coluna em movimento (Trabalhador Y).

Sua saúde teve melhora quando passou a delimitar seus limites pessoais e profissionais. 
Enfrentando as adversidades, deixando bastante claro tanto seus deveres quanto seus direitos de trabalhador, respeitando sua própria jornada de trabalho, evitando excessos, questionando ordens controvérsias, mas dentro da ética e do respeito profissional, assim passou a ser mais respeitado. Associado a isso, também necessitou realizar uma série de tratamentos de reabilitação, entre eles fisioterapia, RPG, pilates por cerca de 3 anos e atualmente pratica atividade física regularmente.

E por último, o caso de um trabalhador, do sexo masculino, 49 anos. Este trabalhador nos chamou bastante atenção pelo nível de envolvimento nas atividades e ações da empresa. Já foi participante da CIPA, do sindicato, representantes dos trabalhadores nos comitês de avanço de nível e promoção da Empresa, enfim durante todo o processo de aquisição buscou ser colaborativo, participativo e segundo ele por isso acabou tendo a sua saúde prejudicada. Para ele, sua saúde é afetada por sua própria culpa, pois como leva muito a sério estas atribuições, se estressa, se desgasta, enfim há uma mobilização intensa em prol das melhorias das condições de trabalho. Pode-se discutir esses dois exemplos a luz de Canguilhem ${ }^{21}$, pois para tratar da questão da saúde desses trabalhadores se faz primeiro necessário compreender o ser vivo, o indivíduo, vivendo sob um meio, que não é estático, imóvel e como um ser normativo, isto é, que a todo o momento renormatiza, cria novas normas, burla outras para tornar esse meio vivível e que é capaz de refletir sobre sua vida, trabalho e saúde, mobilizando-se, gerindo para dar conta das pressões postas e das exigências da sua atividade.

Sendo assim, há sempre uma busca, uma luta incessante e que todo trabalhador na procura de sua saúde tem um papel fundamental, central para obtenção do êxito. Saúde é assim movimento, conquista permanente e entendendo que o trabalho é dinâmico, complexo e variável, e que a todo o momento se faz necessário novas mobilizações dos trabalhadores para a conquista da saúde. Conforme sinaliza Athayde e $\mathrm{Neves}^{22}$ é o compromisso que cada pessoa assume com a sua própria realidade, sendo um campo de negociação constante e permanente.

Estes trabalhadores durante esse processo não estavam estáticos, imóveis e reagindo passivamente ao processo de mudança, mas cada um de seu modo e com suas possibilidades buscou transformar as situações adversas e nocivas.
Teiger ${ }^{23}$, entretanto, nos aponta as dificuldades de analisar e avaliar precisamente as consequências das condições de trabalho no corpo dos trabalhadores, sendo, em geral, avaliados os efeitos que podem ser mensuráveis, quantificados e palpáveis. Estas dificuldades, segundo a autora, advêm de uma série de fatores, dentre eles: o fato da grande parte dos efeitos adversos do trabalho ser produzidos no exterior do seu cotidiano; parte dos efeitos surgirem após longos períodos; e que nas situações de trabalho temos a possibilidade de estudar somente os trabalhadores sadios, isto é, aqueles que conseguiram, apesar das adversidades, permanecerem nos ambientes de trabalho e não aqueles que adoeceram, isto é, que não conseguiram resistir por longos períodos às situações desfavoráveis.

Verificou-se na termelétrica $A$ um número significativo de trabalhadores da área de operação que relataram uma série de riscos na planta neste momento, em decorrência de posturas estereotipadas, falta de acesso a válvulas, enfim alguns problemas relacionados à concepção da termelétrica. De acordo com os trabalhadores, estes problemas estão relacionados ao fato do projeto ter sido desenvolvido para padrões norte-americanos e não brasileiros, portanto, utilizando parâmetros antropométricos elevados para uma realidade de trabalhadores com uma estatura mediana. Na termelétrica $B$ foram entrevistados quinze trabalhadores, sendo que onze identificam que tiveram sua saúde afetada em decorrência das mudanças organizacionais advindas do processo de mudança de propriedade. As queixas mais frequentes se referem a um alto grau de tensão em razão das incertezas do futuro, ansiedade que resultou no aumento do peso ponderal, estresse devido ao aumento da carga de trabalho, pois não houve reposição do efetivo que pediu demissão. Esta diminuição do efetivo trouxe consequências mais sérias quando a UTE voltou a operar sistematicamente, tornando o trabalho mais penoso e sacrificante para os que permaneceram. Também foi relatado por um trabalhador um acidente de trabalho, em decorrência de falha de equipamento, gerando um afastamento de quatro meses.

Ainda hoje se identificam pessoas que sofrem em virtude deste processo e que relatam as dificuldades de adaptação, tendo em seu corpo os reflexos dessa mudança, tais como alterações de pele, gastrite, distúrbios emocionais, entre outros. 


\section{Considerações finais}

Apesar de todas as dificuldades enfrentadas por estes trabalhadores a aquisição foi tida como um ganho, pois era vista como a garantia de seus postos de trabalho e, como trabalhadores assalariados, a manutenção de seus meios de sobrevivência.

Verificou-se que o polo político foi o motivador para que a Empresa de energia entrasse nos consórcios de geração de eletricidade, pois devido ao cenário energético brasileiro tornava-se estratégico para o país e para a Empresa atuar como parceiro das empresas multinacionais. Entretanto, após o apagão energético nos anos de 2001 e 2002, os reservatórios das hidrelétricas retornaram aos níveis normais, tornando-se onerosa e custosa a energia elétrica gerada por termoeletricidade. Consequentemente, a Empresa de energia necessitou realizar aportes financeiros para honrar as cláusulas contingenciais previstas nos contratos destas duas termelétricas.

Nesse contexto emerge o polo mercantil, pois os contratos traziam prejuízos financeiros à Empresa de energia, portanto era necessário renegociá-los, desfazê-los, mas politicamente não era recomendado que os contratos fossem desfeitos. Assim, apresentava-se uma tensão entre estes dois polos: de um lado, o polo mercantil, onde se buscava a obtenção de lucro e a diminuição dos prejuízos; de outro, o polo político, relativo ao bem comum, pois para o país, politicamente não era favorável o rompimento unilateral destes contratos.

Cria-se uma tensão, um debate de valores, que resultou na decisão de compra das UTE com efetivo funcional, isto é, os trabalhadores, pois era menos dispendioso adquirir as unidades do que honrar com os contratos contingenciais durante os cincos anos, conforme previsto nos acordos anteriores.

Neste debate evidenciou-se a ausência de consideração do terceiro polo, o da atividade. A nosso ver, para serem efetivas as mudanças implementadas, é de fundamental importância considerar o ponto de vista da atividade, pois somente assim é possível atingir os objetivos estabelecidos pelos demais polos, em especial o mercantil.

Verificou-se que o fenômeno ocorrido nestas duas UTE é um processo inverso ao das últimas décadas em nosso país, pois a tendência mundial e brasileira nos anos 90 foi de privatização de empresas públicas. Entretanto, evidenciou-se que estas UTE eram da iniciativa privada e passaram para a gestão de uma empresa de economia mista, onde o Estado é o principal acionista. Estas compras às avessas criaram, porém, um vínculo híbrido para estes trabalhadores.

Imagina-se que estas adversidades foram fruto de um processo atípico e novo para a Empresa de energia, pois não foi e nem é possível prever todas estas variáveis e implicações no dia a dia de trabalho, no momento de aquisição. Entretanto, seria de fundamental importância que o processo previsse espaço para que estas lacunas, insuficiências e dificuldades pudessem ser visualizadas e tratadas.

Constatou-se como a ausência de reconhecimento traz consequências para a saúde e a segurança destes trabalhadores, pois inúmeros relatos de sofrimento psíquico, distúrbios emocionais, problemas osteomusculares, alterações gastrointestinais, dentre outras queixas foram evidenciadas. Além de alguns casos de afastamentos laborativos de longa duração, que acarretaram benefícios previdenciários por câncer, acidente de trabalho e doença osteomuscular. Interessante notar que, apesar de todas estas queixas e sintomas, a maioria dos trabalhadores suportou as adversidades. Não se afastaram do trabalho, reagiram e voltaram à normalidade, em um esforço para dar conta do trabalho e em um movimento em prol da sua própria saúde, mesmo que, em alguns casos, de forma inconsciente.

Evidencia-se que hoje é possível introduzir uma série de medidas que podem contribuir para a melhoria das condições de trabalho e, consequentemente, da vida dessas pessoas. Estas mudanças são de cunho organizacional tais como: a melhoria no processo de comunicação das alterações introduzidas, como a implantação do novo plano de saúde; do plano de previdência privada; entre outras que, por ausência de uma comunicação eficaz proporciona nestes trabalhadores um processo de resistência e receio destas modificações.

Além disso, outras questões mais profundas e arraigadas necessitam de um trabalho mais profícuo e duradouro. Estão relacionadas à maior participação destes trabalhadores, consideração de seus saberes e potenciais, perspectiva de crescimento profissional, definição do vínculo empregatício destas pessoas e sentimento de pertencimento à Empresa de energia. É muito importante que essas pessoas possam se reconhecer como participantes do processo, fato que, ainda hoje, não ocorre. 


\section{Colaboradores}

HFS Guida, J Brito e D Alvarez participaram igualmente de todas as etapas de elaboração do artigo.

\section{Referências}

1. Rigotto RM. Inserção da saúde nos estudos de impacto ambiental: o caso de uma termelétrica a carvão mineral no Ceará. Cien Saude Colet 2009; 14(6):2049-2059.

2. Schwartz Y. A comunidade científica ampliada e o regime de produção de saberes. Trabalho e Educação 2000; 7:38-46.

3. Telles A, Alvarez D. Interfaces ergonomia-ergologia: uma discussão sobre trabalho prescrito e normas antecedentes. In: Figueiredo M, Athayde M, Brito J, Alvarez D, organizadores. Labirintos do trabalho: interrogações e olhares sobre o trabalho vivo. Rio de Janeiro: DP\&A; 2004. p. 38-63.

4. Schwartz Y, Durrive Y. Trabalho \& ergologia: conversas sobre a atividade humana. Rio de Janeiro: EDUFF; 2007.

5. Schwartz Y. O trabalho se modifica. In: Schwartz Y, Durrive Y. Trabalho \& ergologia: conversas sobre a atividade humana. Rio de Janeiro: EDUFF; 2007.

6. Schwartz Y. Trabalho e valor. Tempo Social 1996; 8(2):147-158.

7. Canguilhem G. Le normal et le pathologique. Paris: Presses Universitaires de France; 1943.

8. Canguilhem G. Novas reflexões sobre o normal e o patológico. In: Canguilhem G. O normal e o patológico. Rio de Janeiro: Forense Universitária; 1978.

9. Brito J, Athayde M, Neves MY. Caderno de textos: programa de formação em saúde, gênero e trabalho nas escolas. João Pessoa: Editora Universitária UFPB; 2003.

10. Canguilhem G. La santé: concept vulgaire et question pshilosophique. Toulose: Sables; 1990.

11. Dejours C. A loucura do trabalho. São Paulo: Cortez-Oboré; 1992.

12. Dejours C. Addendum: da psicopatologia à psicodinâmica do trabalho. In: Lancman S, Sznelwar LI, organizadores. Christophe Dejours: da psicopatologia à psicodinâmica do trabalho. Rio de Janeiro: Fiocruz; 2004.

13. Athayde MRC. Gestão de coletivos de trabalho e modernidade: questões para a engenharia de produção [tese]. Rio de Janeiro: COPPE, UFRJ; 1996.

14. Guérin F, Laville A, Daniellou F, Duraffourg J, Kerguelen A. Compreender o trabalho para transformálo: a prática da ergonomia. São Paulo: Edgar Blucher; 2001

15. Brasil. Ministério da Saúde (MS). Conselho Nacional de Saúde. Resolução no 196, de 10 de outubro de 1996. Diretrizes e Normas Regulamentadoras de Pesquisas Envolvendo Seres Humanos. Diário Oficial da União 1996; 16 out.

16. Harvey D. Condição pós-moderna: uma pesquisa sobre a modernidade. São Paulo: Loyola; 1992.

17. Antunes R. Adeus ao trabalho? Ensaios sobre as metamorfoses e a centralidade do mundo do trabalho. São Paulo: Cortez; 1995.

18. Clot Y. A função psicológica do trabalho. Petrópolis: Vozes; 2006.

19. Oliveira S, Alvarez D, Brito J. A dimensão gestionária do trabalho: aspectos da atividade de cuidado. Cien Saude Colet 2013; 18(6):1581-1589. 
20. Schwartz Y. Circulações, dramáticas, eficácias da atividade industriosa. Trabalho, Educação e Saúde 2004; 2(1):33-55.

21. Canguilhem G. O normal e o patológico. Rio de Janeiro: Forense Universitária;1995.

22. Athayde MRC, Neves MY. Saúde, gênero e trabalho, na escola: um campo de conhecimento em construção. In: Brito J, Athayde M, Neves MY, organizadores. Saúde e trabalho na escola. Rio de Janeiro: Cesteh, Ensp, Fiocruz; 1998.

23. Teiger C. Las huellas del trabajo. In: Castillo J, Villena J, organizadores. Ergonomia: conceptos y métodos. Madrid: Editorial Complutense; 1998. p. 263-286.

Artigo apresentado em 30/03/2012 Aprovado em 30/06/2013

Versão final apresentada em 23/07/2012 